\title{
POR UMA CURADORIA OPERÁRIA
}

\section{Ana Luisa Lima \\ MAMAM}

\author{
"Ser revolucionário é a profissão natural de um intelectual." \\ Mario Pedrosa em entrevista ao Pasquim
}

No último 28 de outubro, confirmou-se uma tragédia no país. A farsa e a violência foram estratégias muito bem conduzidas para eleger um político, irrelevante nos seus 30 anos de mandatos legislativos, de características fascistas como o $38^{\circ}$. presidente do Brasil. Mais de 57 milhões de pessoas legitimaram a aniquilação da possibilidade de vida plural tornando afrodescendentes, povos originários, a população LGBTI e feministas alvos de tortura e de morte, tanto quanto reiteraram o Partido dos Trabalhadores como um mal a ser extirpado.

É tanto possível, quanto necessário, manifestar muitas críticas contundentes ao PT. Sobretudo, por sua atuação para viabilizar a Usina Hidrelétrica de Belo Monte e, com isso, promover um dos maiores ecocídios e genocídios na região do Xingu que se tem notícia. No entanto, é impossível deixar de reconhecer sua política assertiva em diminuir a miséria do país, dando a oportunidade real de milhões de pessoas muito pobres de ter acesso à alimentação e à universidade pública de qualidade. O Brasil é um jovem' país com um pouco mais de 500 anos. A sua história foi marcada pelo colonialismo imperial, posteriormente, convertido num servilismo político e econômico-financeiro. O PT, por meio do ex-presidente Luiz Inácio Lula da Silva, mesmo com todas as suas contradições, trouxe uma chance de emancipação. A existência do BRICS, por exemplo, foi um protagonismo imperdoável aos velhos países imperialistas.

A retomada do discurso fascista na comunidade global é uma agenda perigosa e tem se demonstrado muito eficiente em reconduzir populações inteiras ao pensamento estreito, violento e preconceituoso. Qualquer negação aos modos plurais de ser e estar no mundo deve servir de alerta a todas e todos que acreditam na liberdade, na igualdade e na fraternidade (um lema francês que merece respeito). Para nós, agentes das artes, esse alerta deve ser nossa maior pauta. A arte não pode servir à opressão, muito pelo contrário, há de ser o escudo mais vigoroso na proteção das populações e grupos de pessoas mais vulneráveis.

Com a demonização mundial do comunismo", uma luta real e constante, tornou-se invisível: a do proletariado. Não são ingênuos (tampouco ufanista, os meus desejos revolucionários), o trabalho árduo e a convergência de pensamentos que, desde o início de minha trajetória, me dediquei a observar, entender e questionar os sintomas do modo capitalista de ser e estar no mundo entranhados no campo das artes.

Então, antes desenvolver alguns pensamentos sobre curadoria, algumas situações precisam ver observadas. São considerações que há muito tenho insistido em retomar, porque o exercício de pensar não pode ser sem fundamento. E as tomadas de posições necessárias de acordo com as circunstâncias pedem.

\section{DO CONTEXTO}

Algo que tem se demonstrado cada vez mais claro é que o marxismo ortodoxo falhou em prever o fim do capitalismo e quando vislumbrou uma sociedade socialista não soube reconhecer a potência da individualidade nessa construção. Há nada de tardio nesse sistema que parece tomar novo fôlego depois de cada crise. Em sua forma atual, sinais fracos das antigas ideologias, nos tornamos simplificados como elementos de dois conjuntos: com dinheiro e sem dinheiro, sem garantia alguma de permanência em um e outro. Assim, um esmagamento sem precedentes do 
sujeito/subjetividade nos tem feito perder até os mais simples parâmetros de pertencimento. Quase já não há conjunções simbólicas que nos contornem: primeiro como coletividade; segundo, como indivíduos. É sem pudor que o neoliberalismo nos fez vulneráveis ao humor da economia. Seja em nome da governabilidade, seja nas decisões aparentemente banais de nosso diariamente: há nada que fuja da baliza econômica. Massa informe, homogeneizada, ainda que seja por meio dos discursos de singularidade, somos parte da grande engrenagem de manutenção do sistema no qual cada desejo mais íntimo é transformado em commodity - vide o Facebook.

Os sinais de fracasso que fizeram celebrar a morte do autor, o fim da história, e das utopias, têm nos feito caminhar para o auge de uma era que passei a chamar de "Finus lato sensu", porque o fim de todos os parâmetros nos parece ser uma finalidade em si mesmo e, esse estado de um "sem finalidade", nos coloca numa perspectiva de "looping", de um "sem fim". Eram os sintomas de fim de uma situação que possibilitava a demarcação de tempo como também a possibilidade de amanhecer novas tomadas de posição. Ao contrário disso, esse modo contemporâneo de percepção, de ser e estar no mundo, parece mesmo se afirmar como existência condensada de espaço-tempo numa aceleração exacerbada criando uma temporalidade sem esquinas.

O campo da arte é espelho dessa condição. E é com arrogância que as artes visuais vociferam ser a primazia da arte, e, quando o discurso lhe interessa, ser um passo além da cultura. O fato é que ninguém está imune. Nenhum de seus agentes (independentes ou institucionais), está fora de viver sob a recorrente necessidade de adaptação pelos manejos retóricos ao sabor caprichoso do mercado. Nos modos do capital já não há um dentro e fora. 0 que é preciso perceber é que há muito se colocaram em marcha ações que sutilmente tornaram privadas as experiências coletivas. Em nome da profissionalização do campo, já não há, em grande escala, qualquer proposição artística em que o coletivo venha antes do privado. Sintomas disso são, cada vez mais legitimadas, as feiras de arte e exposições espetaculares em que o consumo toma o lugar da fruição. O consumo não é outra coisa do que a volta de uma percepção meramente retiniana"I da obra. Como haver produção de diálogos, criação de subjetividades, sem essa possibilidade da experiência estética pelo corpo? Não é a possibilidade dialógica, criadora e criativa, que há nas experiências estéticas que fazem a arte ser eventualmente imaginário coletivo? Respondidas essas perguntas talvez possamos nos dar conta desse perigoso processo que tem feito a arte perder seu valor simbólico para ganhar cada vez mais apenas valor de mercado.

\section{DAS CIRCUNSTÂNCIAS}

Outra pergunta que me ocorre, corolário das anteriores, é: as questões da curadoria são apenas sintomas do modo capitalista em que a arte se deixou engolfar? Notadamente, em nome da profissionalização do campo, o fenômeno da produção artística deixou de ser algo que diz respeito apenas ao artista em seu ateliê. Ao que parece, a produção artística não mais existe sem a mediação institucional-mercadológica que cumpre a dupla função de nomear (legitimar) e demandar. De modo que, dentro dessa lógica, a figura do/a curador/a é menos um agente, mais um/a articulador/a nessa grande engrenagem.

A estrutura pela qual a arte se deixou sucumbir é tão esquizofrênica que a obra em que a priorimovia e era ela mesma produção de conhecimento, nos moldes atuais, tornou-se apenas alvo do manejo retórico laudatório com a finalidade última de especulação do seu valor de mercado. Em outras palavras, o/a artista era o/a produtor/a simbólico que gerava, em torno de si, a produção de conhecimento, e não o contrário. A curadoria, a crítica de arte, e os públicos, diante da produção artística, flexionavam as desinências de acordo com os radicais produzidos pelos/as artistas. De modo que o vocabulário estético era também político, porque se tratava de uma construção dialética dos/as agentes culturais (artista, crítico/a, público, curador/a, etc). Nas condições atuais, o mercado especializou-se em criar demandas de produções artísticas adjetivadas (arte digital, arte política, arte performática, arte vida etc), de tal maneira que as curadorias/editais culturais passaram a impor o vocabulário estético a ser usado pelo/a artista.

Ao que os fatos indicam, criou-se uma lacuna de assuntos que movam debates relevantes sobre arte. O que há é uma produção exacerbada de textos curatoriais que são tagarelices, com pretensões 
filosóficas, em que os trabalhos são apresentados como meras ilustrações de verbetes. Há muito não se vê circular qualquer tipo de debate gerado pela arte que seja de relevância coletiva. Muito pelo contrário, o que se tem visto é o foco voltado para curadores/as cada vez mais tratados/as como celebridades. Em suma, o que se vê nos jornais e revistas internacionais, é um excesso de listas de curadores/as legitimados/as por um mercado que estimula quantidade no lugar da qualidade dos projetos realizados por esses/as.

Se as atuais produções curatoriais são apenas sintomas do modo de ser e estar no mundo ditados pelo capital, outra coisa é certa: o caminho que a arte segue também é um sintoma desse modo de fazer curadoria. $O$ que se pode dizer disso é que a produção artística encurralada nesse jogo de demanda e legitimação tem se deixado repetir em procedimentos e visualidades. Tais repetições dão lugar a um Formalismo Vulgariv em que se torna irrelevante querer flexionar as desinências dos mesmos radicais, não?

\section{O QUE É CURADORIA?}

Talvez, haja uma desvantagem em abordar o assunto sob a perspectiva do que éuma curadoria. Porque no discurso da contemporaneidade, em que 'todas as formas' são possíveis, o fenômeno existe como prática (re)conhecível, inclusive em campos que já ultrapassaram os domínios das artes visuais, ainda que não se possa definir, exatamente, os termos dessa prática. No que diz respeito ao debate, acredito que melhor pergunta fazemos no 'para quê', 'para quem'? Explico: embora exista um esforço em se diluir, criar falsas simetrias, e até mesmo anular, o parâmetro de direita e esquerda na vida política, esse é ainda o único em que consigo encontrar respiro e pulsação para os modos de ser e estar no mundo. E para deixar claro do que estou falando, tomo a liberdade de parafrasear Deleuze (em depoimento que dá numa série de entrevistas conhecida como "O abecedário de Gilles Deleuze"). Ora, ser de esquerda é vislumbrar o horizonte, antes de a si mesmo. É um pensar-agir consciente de que o coletivo vem antes do individual, de que o público vem antes do privado. E isso não passa por uma questão moral, ou uma jornada espiritual altruísta, é uma questão de percepção. Dito isso, para mim, é inevitável que meus questionamentos acerca da curadoria recaiam mais sobre 'para quem', menos no 'como'.

No que se refere à arte, não consigo vislumbrar outro modo de percebê-la senão como política. Penso que já não seja mais necessário dizer que uma arte que se quer política não tem a ver meramente com os conteúdos sociais ou ainda engajamento partidário. Muito pelo contrário, me parece que cada vez mais o político na arte diz respeito à reinvenção dialética dos vocabulários, dos modos de perceber, da instauração de espaços públicos. Cabe dizer ainda que os espaços públicos não são apenas aqueles em que, em tese, qualquer pessoa pode ir-e-vir, mas aqueles espaços em que as pessoas se encontram em plena faculdade de exercer seu direito de falar que é o exercício político por natureza. Como alerta Hannah Arendt "isonomia não significa que todos são iguais perante a lei nem que a lei seja igual para todos, mas sim que todos têm o mesmo direito à atividade política; e essa atividade na polis era de preferência uma atividade da conversa mútua"v .

Então, uma resposta possível à pergunta do 'para quê'/para 'quem' se presta uma curadoria seria isso: a instauração de um espaço público. Lugar em que o diálogo se estabelece sem dirigismos, falsas promessas de interatividade sobre o pretexto de poéticas "relacionais". Ora, a mera interatividade não é em si um 'espaço' construído para o diálogo. Entende-se por obras interativas aquelas em que o/a fruidor/a precisa agir-com para que a obra aconteça. O problema é que esse agir-com, recebido com tanto entusiasmo em nosso meio, pode mascarar a inabilidade de algumas obras de se deixar construir, efetivamente, pela ação, bem como impede que o/a fruidor/a se construa a partir da experiência. Por exemplo, as obras que nos incitam unicamente a reagir aos estímulos propostos, e que os resultados já são previstos. Logo, não podemos falar em construção: nem do ponto de vista da obra, nem do/a fruidor/a que passa a ser mero aparato estético desta. Assim, falo de um lugar em que a experiência estética por si mesma é condutora de diálogos com todo e qualquer público. Nesse sentido, cada vez mais me assusta uma naturalização da privatização da experiência coletiva, como se a mera organização de qualquer exposição já fosse por si mesma uma promessa de experiência que leva as construções de subjetividade. Sabemos que não. 
Outro problema grave que tem sido tratado como natural sob a luz do mercado, é a precarização do trabalho tanto do/a artista, quanto do/a curador/a. Ativados por demandas excessivas de exposições, em sua maioria de interesse privado, em nome da necessidade de visibilidade, e subsistência, tanto o/a artista quanto o/a curador/a acabam se submetendo a exercerem multi-funções com remunerações irrisórias, ou, nenhuma. Então, a ideia de que temos atuado dentro de um programa de curadoria operária é fato. Infelizmente, menos em nome de um pensamento ideológico de busca por mudanças efetivas na vida política e civil, mais por nos deixarmos reproduzir essa condição 'industrial' no campo das artes sem o menor pudor.

\section{UM OLHAR POSSÍVEL}

Há, no entanto, que se forjar, pelo menos, outros modos de caminhada nem que seja para implodir, desconstruir, o que parece ser um caminho sem volta. E eu não vejo maneira de fazê-lo senão seguir perguntando, questionando, propondo outras formas de. Já perceberam quanto Políticae Sujeito são temas constantes na arte contemporânea? Tais verbetes, contudo, são invocados nos eventos de artes, menos para ser discutidos, questionados, ampliados, e mais para servir de justificativa enquanto "qualidade filosófica" de tais eventos. É preciso uma nova subjetividade que acenda a discussão da necessidade de (re) pensar os valores da obra de arte enquanto construção de um imaginário simbólico coletivo. Um modo de assegurar a preponderância da experiência estética em si mesma, no lugar de (re) naturalizar a aura do caráter objetual da obra. O conceito de nova subjetividade ainda é algo em construção cuja a base se encontra no legado da Nova Objetividade, que segundo Hélio Oiticica se estrutura a partir das seguintes ideias:

\footnotetext{
“1 - vontade construtiva geral;

2 - tendência para o objeto ao ser negado e superado o quadro de cavalete;
}

3 - participação do espectador (corporal, táctil, visual, semântica, etc.);

4 - abordagem e tomada de posição em relação a problemas políticos, sociais e éticos;

5 - tendência para proposições coletivas e conseqüente abolição dos "ismos" característicos da primeira metade do século na arte de hoje (tendência esta que pode ser englobada no conceito de "arte-pós-moderna" de Mário Pedrosa);

6 - ressurgimento e novas formulações do conceito de antiarte."

Penso que embora Oiticica tenha conseguido clarificar bem os termos da produção artística daquele momento como "um estado típico de arte brasileira", ainda assim, recorrentemente hoje quando se voltam para aquele momento histórico da arte o fazem cada vez mais sob termos formalistas e menos políticos. Como se o contexto histórico daquela produção fosse mero substrato da obra e não parte integrante de sua própria constituição. Acredito que algumas manifestações artísticas atuais estão profundamente entranhadas do legado deixado pela Nova Objetividade, ainda que o ponto de partida não seja mais um desejo de objetividade, mas de subjetividade.

É pensando sobre isso que proponho um olhar sobre a atual arte contemporânea brasileira. Ao contrário do que se pode imaginar não existe de fato uma ruptura entre aquele momento histórico e o atual. Apenas os modos de criação parecem tomar sentidos inversos do que aqueles, ainda que permaneçam, no fim, numa mesma direção. Ora, na Nova Objetividade era o substrato social, coletivo, que acionava a criação e a forma encontrava singularidade em cada artista. Hoje, pensando na maioria dos trabalhos que se vê, tanto nos discursos dos/as artistas, o substrato que impulsiona a criação é assunto individual, particular, subjetivo, mas encontra na forma um modo de se tornar assunto que diz respeito ao coletivo.

Se naquele momento anterior, era luta pelos direitos políticos que fez mover o desejo de uma experiência estética construtivista, para uma coletividade, nesse momento de crescente esmagamento dos direitos civis, a que temos sido submetidos, os trabalhos de arte que afirmam subjetividades - que ao mesmo tempo dão vozes a alteridades - tomam lugar ainda mais relevantes no que diz respeito à saúde política de uma sociedade civil. Nesse momento, como já o disse anteriormente, em que os parâmetros de pertencimento tem sido reduzido ao campo econômico, a experiência do sujeito (mais do que sua apresentação e/ou representação) inscrito nas mais diversas paisagens históricas, políticas e sociais é o programa estético coletivo mais urgente que temos hoje. 


\section{UMA PESQUISA CURATORIAL}

Sempre tive pudores de me apresentar como curadora, porque além de haver um recorrente equívoco de efeito hierárquico entre as/os agentes do campo da arte, eu não entendo curadoria como profissão, mas função que um/a artista, crítico/a, historiador/a, pesquisador/a, etc, podem vir a desempenhar. E penso que tal função deve ser desempenhada com ética, em nome de um interesse coletivo - ainda que quase sempre seja inevitável o uso de recursos privados. Nesse sentido, só a pouco tempo, depois de muitos anos de trabalho desenvolvido como pesquisadora e crítica de arte, me vi com alguma proposição a ser apresentada que traz à tona todos esses questionamentos que tenho feito até então numa pergunta inevitável: como construir uma Nova Subjetividade?

Essa pesquisa tem encontrado diálogos com artistas que em seus trabalhos se apresentam como sujeitos, quando seus corpos são corpospolíticos dentro de paisagens históricas, culturais, sociais diversas. Vale entender esse corpo não só como corpo-encarnado, mas corpo-gesto, em que embora o corpo não esteja presente em cena, o gesto de sua passagem não deixa de trazer à superfície as narrativas de alteridade: sejam sobre imigração, gênero, raça, diversidade cultural, (in) tolerância religiosa, disparidade econômica, etc.

\section{ARTISTAS}

Rubiane Maia

http://cargocollective.com/rubianemaia

Rodrigo Braga

http://www.rodrigobraga.com.br/

Juliana Notari

http://issuu.com/juli09/docs/juliananotari\#

Tom N / Luísa Nóbrega

http://www.luisanobrega.com/

Leonora Weissmann

https://www.leonoraweissmann.org

Thiago Martins de Melo

http://www.mendeswood.com/artists/15/bio
Ícaro Lira

http://cargocollective.com/icarolira

Luana Navarro

http://www.luananavarro.com/

Mavi Veloso

http://maviveloso.tumblr.com/

Dalton Paula

https://daltonpaula.com/

Paulo Nazareth

http://artecontemporanealtda.blogspot.com.br/ Mai Fujimoto

http://maifujimoto.weebly.com/

\section{CONSIDERAÇÕES FINAIS}

Nesse marulho inevitável de vozes em uníssono segundo a maré das crises e novos fôlegos do capital, faço votos que tenhamos algum ânimo de resistir a tal movimento. Que nosso operariado esteja em vias de aniquilar esse sistema que teima em esmagar as convergências simbólicas que asseguram aquilo que ainda há de humano em nós.

\section{NOTAS}

I. Importante deixar claro a diferença do entendimento do Brasil como país geopolítico criado a partir da invasão de países imperialistas e o Brasil que deve ser entendido como território plurinacional em função dos seus povos originários. Na Bolívia esse reconhecimento de que há duas realidades de entendimento de fundação país a serem percebidas deu lugar a uma das leis mais belas já criadas: Ley Marco de la Madre Tierra y Desarrollo Integral para Vivir Bien, Bolívia, 2012.

II. É preciso separar as experiências catastróficas dos governos ditatoriais comunistas com o ideário/legado marxista que ainda serve de bússola frente à toda opressão capitalista.

III. No Brasil, com o legado dos movimentos Concretos e Neoconcretos, há uma tomada de consciência de que a fruição artística que prioriza a visão (a retina) é uma tradição europeia. Nossos movimentos preconizam que a fruição é participativa na qual a sensação e memória são 
ativadas por todos os modos de percepção do corpo apto a construir suas subjetividades.

IV. O Formalismo Vulgar foi um conceito que criei para discutir as formas e procedimentos artísticos que se repetem na arte contemporânea em função do mercado. Ao contrário dos movimentos modernistas/da modernidade, a contemporaneidade não criou um programa político-formal como cubismo, surrealismo, etc. Mas é possíveis identificar um formalismo, através das formas se repetem de maneira exaustiva (por isso, vulgar) pelo desejo de visibilidade dos/ as artistas que fazem caber seus trabalhos em projetos curatoriais, editais, becas, etc.

V. Trecho do seu livro "O que é Política?"

\section{SOBRE A AUTORA}

Ana Luisa Lima é crítica de arte, escritora e pesquisadora independente com foco em literatura e artes visuais - imagem e narrativa. Nasceu em Recife, atualmente baseada em Salta - Argentina. Faz parte do Conselho Curatorial do Museu de Arte Moderna Aloísio Magalhães - MAMAM. Editora da revista Tatuí de crítica de arte. Participou de debates, promoveu residências editoriais, ministrou laboratórios de escrita em crítica de arte e de análise dos discursos em artes visuais em vários estados brasileiros. Cocuradora do projeto ‘Poemas aos homens do nosso tempo - Hilda Hilst em diálogo', Programa Rede Nacional Funarte $9^{a}$ edição, 2013. Criadora da Cigarra Editora. Autora do livro '16'39" a extinção do reino deste mundo', São Paulo-SP, 2015. No audiovisual, lançou seu primeiro curta-metragem 'Zona Habitável' (13', Nova Lima - MG, Brasil, 2015). Já fez curadorias e publicou ensaios sobre artistas e fotógrafos como Farnese de Andrade (BR), Luiza Baldan (BR), Yuli Yamagata (BR), Marcelo Silveira (BR), Nazareno $(B R)$, Thiago Martins de Melo (BR), Felipe Abreu (BR), Carolina Krieger (BR), Luana Navarro (BR), Marco Maria Zanin (IT), Serge Huot (FR), Stéphane Pauvret e Christine Laquet (FR). Seus ensaios já foram traduzidos e publicados em espanhol, inglês, francês e italiano. 